\title{
Influence of cadmium sulfide nanoparticles on structural and electrical properties of polyvinyl alcohol films
}

\author{
J. Koteswararao ${ }^{1}$, R. Abhishek ${ }^{1}$, S. V. Satyanarayana ${ }^{2}$, G. M. Madhu ${ }^{*}$, V. Venkatesham ${ }^{1}$ \\ ${ }^{1}$ Department of Chemical Engineering, M S Ramaiah Institute of Technology, 560054 Bangalore, Karnataka, India \\ ${ }^{2}$ Department of Chemical Engineering, Jawaharlal Nehru Technological University Anantapur, Anantapuramu - 515002, \\ Andhra Pradesh, India
}

Received 1 January 2016; accepted in revised form 20 June 2016

\begin{abstract}
Cadmium sulfide (CdS) nanoparticles have been synthesized by hydrothermal method and dispersed in poly vinyl alcohol (PVA) matrix in varying amounts by weight. Subsequently, PVA/CdS nanocomposites have been synthesized with the objective of investigating the effect of CdS nanoparticles on structural and electrical properties of PVA films. Structural properties were analyzed by Fourier transform infrared spectroscopy (FTIR), X-ray diffraction (XRD) and scanning electron microscopy (SEM) techniques. Differential scanning calorimetry (DSC) was used to investigate thermal properties of PVA/CdS nanocomposites. Electrical properties were measured by using high frequency LCR meter and were found to be strongly dependent on frequency and nano CdS content. Dielectric constant decreased with increase in frequency and with increase in nanofiller concentration. AC conductivity and dielectric loss increased with frequency and decreased with increase in nano CdS content.
\end{abstract}

Keywords: nanocomposites, cadmium sulfide, electrical properties, polyvinyl alcohol

\section{Introduction}

Use of nanoparticles in numerous applications has become a major area of interdisciplinary research in recent times. The method of nanoparticle synthesis is an important factor in determining the type of application. The research, particularly on semiconductor nanoparticles is motivated by its possible uses in various fields like nonlinear optics, solar cells, lightemitting devices, electronics, biological labels, and catalysis. The size-dependent mechanical, optical and electronic properties are very much essential. When a particle approaches the size of a few nanometers, its diameter becomes equal to or less than the bulk semiconductor exciton diameter (for cadmium sulfide it is 5-6 nm [1]), such that quantum confinement of electron-hole pairs increase the band gap relative to that in the bulk materials. Hence, the control of particle size allows tuning of the band gap which gives the desired above mentioned electronic and optical properties. Reinforcement of inorganic nanoparticles inside solid polymer matrices are attracting increased attention because the combination of both these materials provides a simple route to stable and processable materials having properties of both components incorporated in the matrix [1].

However, these composites normally cannot be re-dissolved while protecting the colloidal state of nanoparticles. The single polymer molecule represents an important type because isolated nanocomposites based on a single molecule can be obtained, which have very desirable processing characteristics. Mainly, all the applications which are based on single polymer molecule can be applied to the single molecule-nanoparticle composites also. In most of these cases, the nano-

$\overline{{ }^{*} \text { Corresponding author, e-mail: gmmadhu@gmail.com }}$

(C) BME-PT 
composites were further used in various applications in their thin-film form [1].

Composite materials consisting of metal nanoparticles embedded in transparent host matrix have attracted the attention of researchers as advanced technological materials for use in solar cells for photoelectric conversion, transistors for electronic switches [2-6] because of their unique optical, electronic [7], mechanical [8] and structural [9] properties. Large interfacial area between the nanofiller and polymer matrix is a key advantage of nanocomposites since the nanomaterials have high aspect ratio and high surface area. Similarly the dielectric properties of polymers doped with micro and nano fillers have also attracted considerable attention, due to their technological importance for devices such as heating elements, electrical igniters, electrodes for fuel cells and crucibles for vacuum induction furnaces and electric feed [10]. Polymer nanocomposites are known to possess good barrier, mechanical properties, reduced flammability, increased heat distortion temperature and reduced solvent uptake [11].

The study of the effect of temperature on dielectric and frequency is one of the most convenient and sensitive methods of investigating polymer structure. The polarization of dielectric is contributed by dielectric, polar and ionic means [12]. Electronic polarization occurs during very short intervals of time, ionic polarization in the range of a few seconds whereas the dipole polarization takes relatively longer durations.

In this study, poly vinyl alcohol (PVA) has been used as a host matrix for incorporating cadmium sulfide (CdS) nanoparticles due to its water soluble, transparent and highly durable nature. It is a semi-crystalline hydrophilic polymer with a 1,3 glycol structure. Due to its biodegradability and non-toxicity it is highly suitable for environmental processes $[13,14]$. The primary focus here is to explore the effects of $\mathrm{CdS}$ nanoparticles loading on properties of PVA/CdS composite films. Crystallinity of pure $\mathrm{CdS}$ nanopowder and prepared PVA/CdS nanocomposites was studied by X-ray diffraction (XRD) analysis. Scanning electron microscopy (SEM) and Fourier transform infrared spectroscopy (FTIR) techniques were used to investigate the surface morphology of prepared films and influence of CdS nanoparticles on structural characteristics of PVA films. The dielectric constant, dielectric loss and conductivity of PVA/CdS nanocomposite films at different frequencies were studied in order to probe the role of nanofiller in PVA matrix. Also, the effect of CdS content on thermal properties of PVA/CdS nanocomposites was investigated in detail.

\section{Experimental procedure}

\subsection{Reagents and materials}

All chemicals used were of analytical grade and used without further purification. Cadmium nitrate, $\left[\mathrm{Cd}\left(\mathrm{NO}_{3}\right)_{2} \cdot 4 \mathrm{H}_{2} \mathrm{O}(\geq 99 \%)\right]$, Nice Chemicals Pvt. Ltd, Cochin, India, Thiourea [NH2CSNH2] AR grade $(\geq 99 \%)$, and L-valine $\left[\mathrm{C}_{5} \mathrm{H}_{11} \mathrm{NO}_{2}\right] \mathrm{BO}$ grade were obtained from SDFCL (SD Fine-CHEM LIMITED), Mumbai, India. PVA $\left.\left[\mathrm{C}_{2} \mathrm{H}_{4} \mathrm{O}\right)_{\mathrm{n}}\right]$ LR grade having molecular weight from 85000 to 124000 (86-89\%) was obtained in powder form from SDFCL (SD Fine CHEM LIMITED), Mumbai, India. Double distilled water was used for dissolution and casting of PVA films.

\subsection{Synthesis and characterization of $\mathrm{CdS}$ nanoparticles}

CdS nanoparticles were prepared using hydrothermal method $[15,17]$. An aqueous solution was prepared by mixing $3.08 \mathrm{~g}$ of Cadmium nitrate $\left(\mathrm{Cd}\left(\mathrm{NO}_{3}\right)_{2} \cdot 4 \mathrm{H}_{2} \mathrm{O}\right), 2.285 \mathrm{~g}$ of Thiourea $\left(\mathrm{NH}_{2} \mathrm{CSNH}_{2}\right)$ and $0.3518 \mathrm{~g}$ of $\mathrm{L}$-valine $\left(\mathrm{C}_{5} \mathrm{H}_{11} \mathrm{NO}_{2}\right)$ were dissolved in $80 \mathrm{~mL}$ of distilled water to form a solution. Here, thiourea and L-valine act as fuel and stabilizer respectively. The fuel used here supplies required energy for the reaction. The solution is kept in teflon lined stainless steel container and stirred for $30 \mathrm{~min}$ utes. Then the container was placed in an autoclave at a temperature of $180-200^{\circ} \mathrm{C}$, for 4 hours, and later allowed to cool to room temperature. The product was then washed thoroughly with distilled water and ethanol, and centrifuged. The residue was heated at $80^{\circ} \mathrm{C}$ for an hour to produce nano powder of CdS. The overall reaction can be represented as shown by Equation (1):

$$
\begin{aligned}
\mathrm{Cd}\left(\mathrm{NO}_{3}\right)_{2}+ & \mathrm{NH}_{2} \mathrm{CSNH}_{2} \\
& \rightarrow \mathrm{CdS}+2 \mathrm{~N}_{2} \mathrm{O}+2 \mathrm{H}_{2} \mathrm{O}+\mathrm{CO}_{2}
\end{aligned}
$$




\subsection{Fabrication of PVA/CdS nanocomposite films}

PVA/CdS nanocomposite films were prepared by solution intercalation film casting method. Films were cast from a CdS water suspension, in which PVA was dissolved by heating at $75-80^{\circ} \mathrm{C}$ for $4 \mathrm{hr}$ with constant stirring on a water bath. The solid content of the PVA solution was maintained at $7.5 \%$ by wt. The solution was then ultrasonicated at $80-90^{\circ} \mathrm{C}$ for 30 $40 \mathrm{~min}$ for uniform distribution of nanomaterial in the solution and to minimize any possible agglomeration and immediately poured into a clean glass mould and then dried at room temperature for 48 hours. PVA nanocomposite films were cast with different solutions containing varying amounts viz. $0.5,1,1.5$ and $2 \mathrm{wt} \%$ of CdS nanoparticles. The casted films were free from air bubbles with uniformly dispersed CdS nanoparticles in PVA matrix. The thickness of the nanocomposite film samples casted were in the range of $0.18-0.22 \mathrm{~mm}[16]$.

\subsection{Measurements}

FTIR spectra of the samples were measured in the spectral range of $4000-500 \mathrm{~cm}^{-1}$ using FTIR in transmittance mode with resolution of $4 \mathrm{~cm}^{-1}$. XRD analysis was recorded using Brucker's D-8 advanced wide-angle $\mathrm{X}$-ray diffractometer. The $\mathrm{X}$-ray source was Ni-filtered $\mathrm{Cu}-\mathrm{K} \alpha$ radiation $(40 \mathrm{kV}, 30 \mathrm{~mA})$. The dried membranes of uniform thickness $(\sim 200 \mu \mathrm{m})$ were mounted on a sample holder and the X-ray tracings were recorded in the range of $0-80^{\circ}$ at a speed of $8^{\circ}$ per min. Surface images were recorded by SEM (Model JSM-5910-JEOL JAPAN) at an operating voltage of $5 \mathrm{kV}$. For the electrical characterization of composites, high frequency LCR meter (Agilent 4294A) was employed having a frequency range from $4 \mathrm{kHz}$ to $1 \mathrm{MHz}$. The test was carried out at constant voltage of $1 \mathrm{~V}$ and at room temperature. DSC measurements of neat PVA and PVA/CdS nanocomposites were performed using a NETZSCH DSC $200 \mathrm{~F} 3$ instrument in the temperature range of 30 to $250^{\circ} \mathrm{C}$ in nitrogen atmosphere. Both the heating and cooling rates were maintained at $10^{\circ} \mathrm{C} \cdot \mathrm{min}^{-1}$.

\section{Results and discussion \\ 3.1. Fourier transform-infrared spectroscopy (FTIR)}

Any possible interaction between PVA matrix and CdS nanoparticles can be understood by FTIR analysis. The FTIR spectra of PVA and CdS reinforced PVA nanocomposite films are shown in Figure 1. The spectrum shows peaks at 3285, 2923, 1724, $1373,1239,1087$, and $842 \mathrm{~cm}^{-1}$. The broad peak around $3285 \mathrm{~cm}^{-1}$ indicates stretching of hydroxyl groups $(\mathrm{O}-\mathrm{H})[40]$ and peaks at 2923 and $2850 \mathrm{~cm}^{-1}$ are due to $\mathrm{C}-\mathrm{H}$ asymmetric stretching vibration. The peaks observed at 1724 and $1373 \mathrm{~cm}^{-1}$ correspond to $\mathrm{C}=\mathrm{O}$ stretching (of vinyl acetate group of PVA), out-of-phase deformation and in-plane deformation of the methyl group respectively. The peak at $1239 \mathrm{~cm}^{-1}$ corresponds to the $\mathrm{C}-\mathrm{O}-\mathrm{C}$ out of phase stretching and the peak at $1087 \mathrm{~cm}^{-1}$ was due to the COS stretching vibration mode and also indicates the $\mathrm{C}-\mathrm{O}$ stretch of secondary alcoholic groups. Out-of-

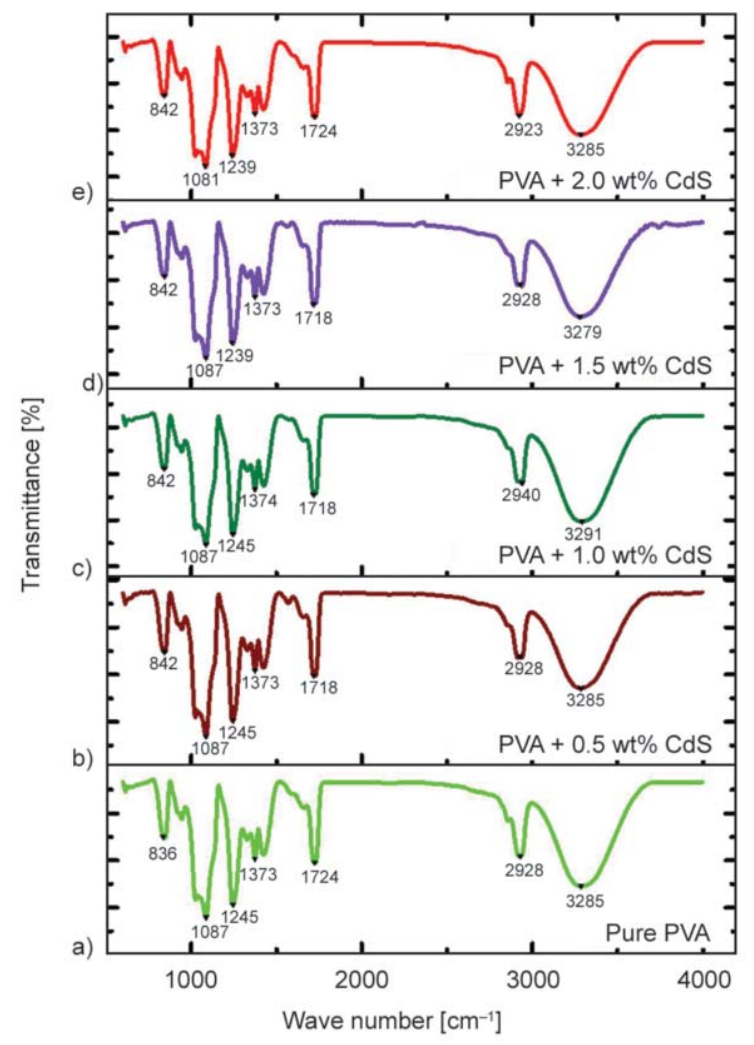

Figure 1. FTIR samples of PVA loaded with CdS nanoparticles at (a) $0 \mathrm{wt} \%$, (b) $0.5 \mathrm{wt} \%$, (c) $1.0 \mathrm{wt} \%$ (d) $1.5 \mathrm{wt} \%$, (e) $2 \mathrm{wt} \%$ 
phase stretching vibration was observed at $842 \mathrm{~cm}^{-1}$ due to sulfate ions in are linked with water molecules by hydrogen bonding [41].

The vibration absorption peak of $\mathrm{Cd}-\mathrm{S}$ bond at $405 \mathrm{~cm}^{-1}$ is observed in the spectrum. The observed at peak at $3285 \mathrm{~cm}^{-1}$ is very broad when compared to the as synthesized complex, which is purely due to the adsorbed moisture by the sample. The peak observed at $2923 \mathrm{~cm}^{-1}$ evidences the capping of alkyl group over the formed CdS. There was no form of additional peak in IR spectra; however a small shift in the peak position of the band is observed (which is not considerable) corresponding to $\mathrm{C}=\mathrm{O}$ stretch and $\mathrm{C}-\mathrm{O}-\mathrm{C}$ stretch vibrations indicates physical interaction between hydroxyl groups of PVA and nano CdS. The hydroxyl groups of PVA have a very strong tendency to form charge-transfer complex with $\mathrm{CdS}$ nanoparticles through chelation.

\subsection{X-ray diffraction analysis}

Figure 2 shows XRD patterns of the synthesized CdS nanoparticles. Comparison with the standard (JCPDS No 41-4019) [15] clearly revealed the formation of single phase $\mathrm{CdS}$ with a hexagonal crystal structure. The crystalline nature of pure nano $\mathrm{CdS}$ was observed by various sharp peaks shown in Figure 2. Seven separate diffraction peaks can be seen at the $2 \theta$ values of $24.98,26.5,28.14,31.8,43.8,48.2$ and $51.9^{\circ}$. It was observed that varying the solvent during synthesis of nano $\mathrm{CdS}$ presented preferential growth in different crystalline directions [18]. Similarly it can be believed that a less pronounced preferential growth occurred in the nanocomposite film samples of this study.

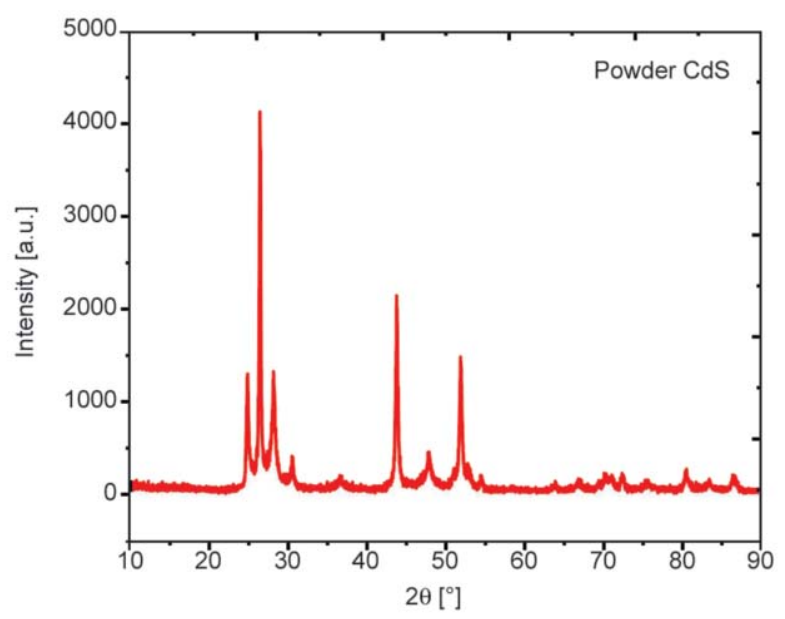

Figure 2. XRD profile of pure CdS nanoparticles

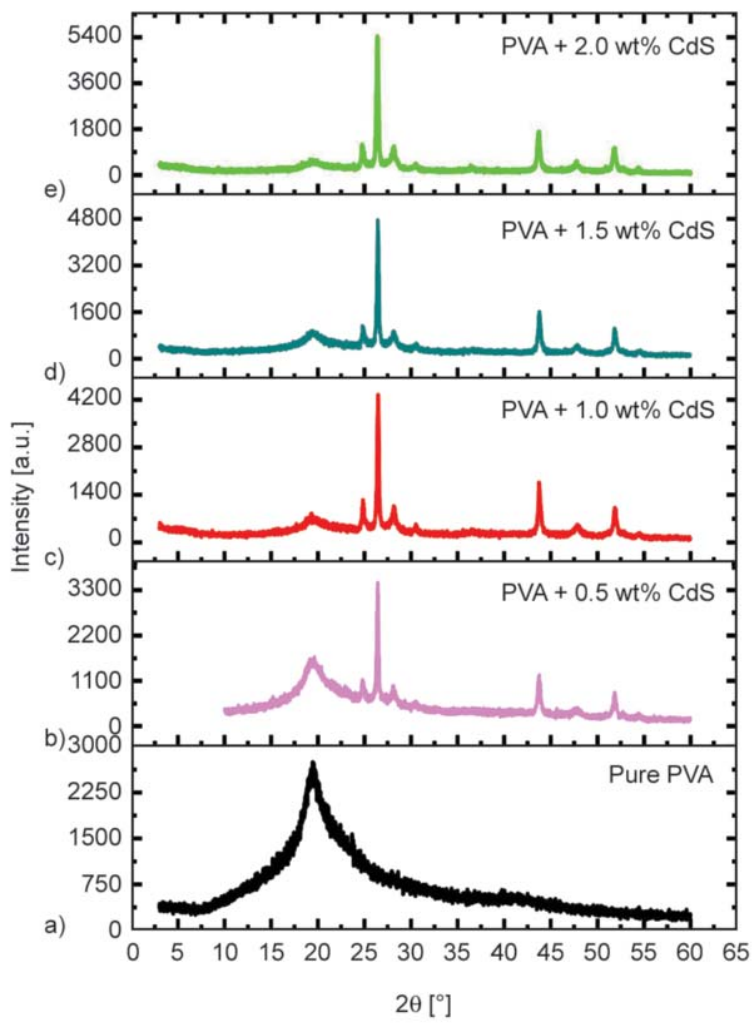

Figure 3. XRD profiles of (a) $0 \mathrm{wt} \%$, (b) $0.5 \mathrm{wt} \%$, (c) $1 \mathrm{wt} \%$, (d) $1.5 \mathrm{wt} \%$, (e) $2 \mathrm{wt} \%$ CdS nanoparticles loaded PVA nanocomposites

XRD patterns of pure polyvinyl alcohol and PVA/CdS nanocomposites having $0.5,1,1.5$ and $2 \mathrm{wt} \%$ of $\mathrm{CdS}$ respectively are shown in Figure 3 . All the composites showed a peak at approximately $2 \theta=19.4^{\circ}[19]$ corresponding to $\left(\begin{array}{lll}1 & 0 & 1\end{array}\right)$ crystal plane for polyvinyl alcohol, which indicates the semi-crystalline nature of PVA. The crystalline nature of PVA results from the strong intermolecular interaction between PVA polymer networks. The mean particle size of synthesized nano CdS calculated by using Scherrer equation was found to be $37.68 \mathrm{~nm}$.

$\mathrm{XRD}$ profiles of the composites showed no shifting or broadening of peak at $2 \theta=19.4^{\circ}$, but showed appearance of smaller new peaks at $24.98,26.4,28.16$, $30.65,44.33,47.92,51.81$ and $54.48^{\circ}$ which clearly indicated the presence of $\mathrm{CdS}$ nanoparticles inside the PVA matrix.

\subsection{Thermal characterization of the PVA/CdS nanocomposites}

Differential scanning calorimetry (DSC)

The thermal properties of PVA/CdS composite films were analyzed by DSC [39] to investigate the effect of CdS filler content on glass transition temperature 
$\left(T_{\mathrm{g}}\right)$, melting temperature $\left(T_{\mathrm{m}}\right)$, heat of fusion $(\Delta H)$, percentage crystallinity $\left(\% x_{\mathrm{c}}\right)$ and crystallization temperature $\left(T_{\mathrm{c}}\right)$ of PVA. DSC analysis was performed in successive cycles of heating and cooling as shown in Figure 4. Outline of the DSC data corresponding to these curves is shown in Table 1.

During heating of a sample, for example, from room temperature to its decomposition temperature, peaks with positive and negative $\Delta \mathrm{d} H / \mathrm{d} t$ may be recorded; each peak corresponds to a heat effect associated with a specific process, such as crystallization or melting. The important information from DSC curves is the temperature at which process occurs and the peak temperature is associated and the temperature at which maximum reaction rate occurs.

The analysis was carried out from 25 to $250^{\circ} \mathrm{C}$ of temperature at a rate of $10^{\circ} \mathrm{C} / \mathrm{min}$. All peak values have been shown in Table 1. The incorporation of CdS nanoparticles decreased the $T_{\mathrm{g}}$ and $T_{\mathrm{m}}$ of PVA. This decrease may be due to the agglomeration of $\mathrm{CdS}$ nanoparticles, which decreases the polymeric network strength and also the intermolecular inter-

Table 1. Thermal properties of PVA/CdS nanocomposites showing $T_{\mathrm{g}}, T_{\mathrm{m}}, \Delta H_{\mathrm{m}}, \% x_{\mathrm{c}}$ and $T_{\mathrm{c}}$ as a function of $\mathrm{CdS}$ content in PVA matrix

\begin{tabular}{|c|c|c|c|c|c|c|}
\hline \multicolumn{2}{|c|}{$\begin{array}{c}\text { Composition } \\
{[w t \%]}\end{array}$} & \multirow{2}{*}{$\begin{array}{c}T_{\mathrm{g}} \\
{\left[{ }^{\circ} \mathbf{C}\right]}\end{array}$} & \multirow{2}{*}{$\begin{array}{c}T_{\mathrm{m}} \\
{\left[{ }^{\circ} \mathbf{C}\right]}\end{array}$} & \multirow{2}{*}{$\begin{array}{l}\Delta \boldsymbol{H}_{\mathrm{m}} \\
{[\mathrm{J} / \mathrm{g}]}\end{array}$} & \multirow[t]{2}{*}{$\% x_{c}$} & \multirow{2}{*}{$\begin{array}{c}T_{\mathbf{c}} \\
{\left[{ }^{\circ} \mathbf{C}\right]}\end{array}$} \\
\hline PVA & $\mathrm{CdS}$ & & & & & \\
\hline 100.0 & 0.0 & 81.6 & 224.3 & 40.54 & 4.390 & 189.8 \\
\hline 99.5 & 0.5 & 71.3 & 189.1 & 40.89 & 5.768 & 95.2 \\
\hline 99.0 & 1.0 & 68.4 & 190.2 & 41.49 & 4.572 & 118.5 \\
\hline 98.5 & 1.5 & 71.2 & 191.5 & 37.29 & 4.408 & 109.9 \\
\hline 98.0 & 2.0 & 69.2 & 190.0 & 35.72 & 4.171 & 118.6 \\
\hline
\end{tabular}

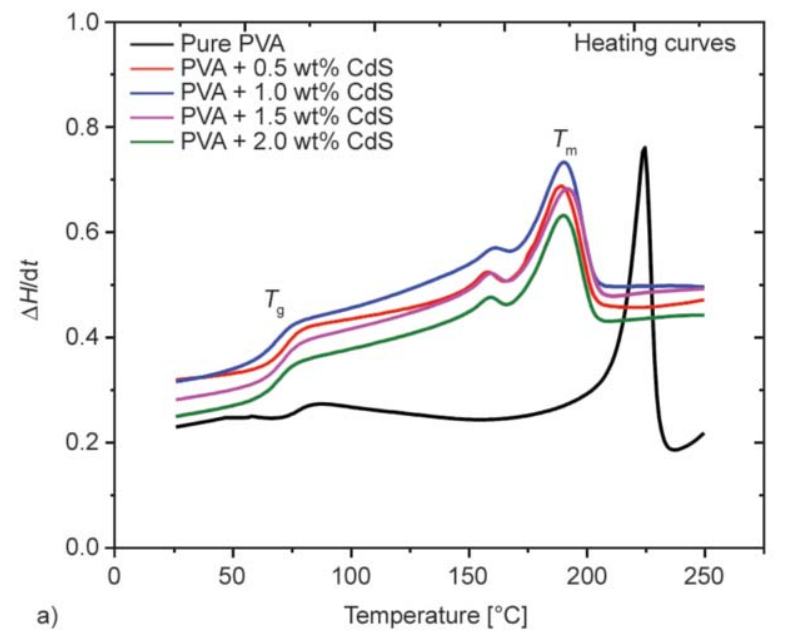

action between PVA chains. The values of $T_{\mathrm{g}}$ and $T_{\mathrm{m}}$ do not vary much with the content of $\mathrm{CdS}$ in the matrix which indicates that the PVA barely interacts with the nanoparticles. It may be due to increase in the free volume (which may also be due to adsorption because of the limited mobility of the adsorbed chains). The suppressed melting point shows that the interaction with the nanofiller hampers crystallization. This may also explain the larger supercooling (lower $T_{\mathrm{c}}$ ).

Although an increase in the nanoparticle content does not affect crystallinity (melting enthalpies in Table 1 are almost unchanged), it can be concluded that the presence of the CdS-nanofiller prevents crystal thickening. The observed effects can be explained by the reduced mobility of the PVA chains attached to the surface of the CdS nanoparticles. This is also supported by the FTIR data given above.

The glass transition, strictly speaking, is not a true phase transition, because the first derivative of the heat capacity curve is a continuous function of temperature as shown by phase-modulated DSC measurements. This means that the polymer shows signs of a spectrum of glass transition temperatures, each corresponding to different segmental relaxations. Figure 4 tells not just a shift of the slope in the heat capacity curve to higher temperatures with an increase of the content of the inorganic phase, but also a lengthening of its temperature range. It seems that incorporation of $\mathrm{CdS}$ into the polymer matrix affects the distribution of chain segments, most likely due to a change in chain packing density in the surrounding area of the surface of the nanofillers.

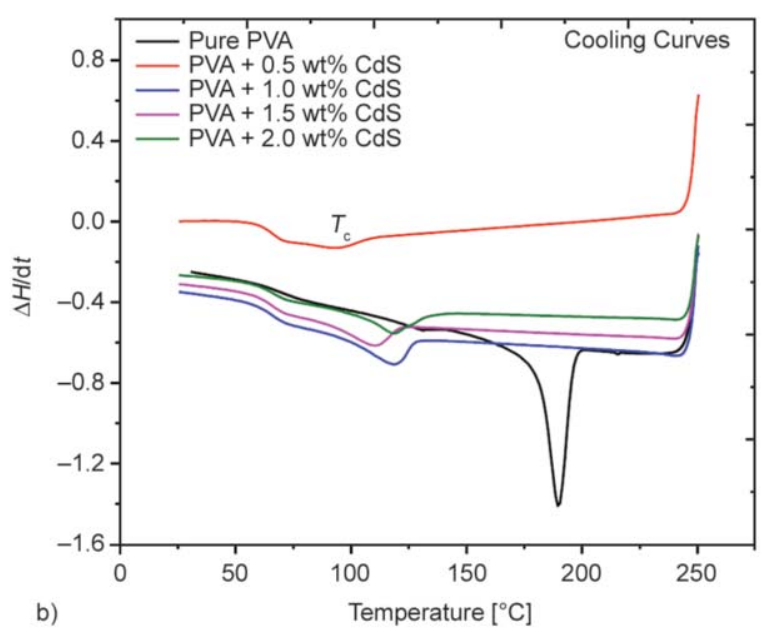

Figure 4. (a) DSC heating curve and (b) cooling curve of pure PVA and PVA/CdS nanocomposites 


\subsection{Scanning electron microscopy (SEM)}

Surface morphology of PVA and PVA/CdS nanocomposite films was understood from the SEM images shown in Figures 5. The images clearly show CdS nanoparticles which have porous, agglomerated, acicular (Needle like components) structure, size below $80 \mathrm{~nm}$ and also confirmed from the images reported elsewhere [20,21]. The varying sizes obtained may be due to agglomeration of the nanoparticles which takes place in order to minimise the high surface energy that exists in individual nanoparticles. Figure 6 shows SEM images of (a) neat PVA, (b) PVA$0.5 \mathrm{wt} \% \mathrm{CdS}$, (c) PVA-1.0 wt $\%$ CdS, (d) PVA$1.5 \mathrm{wt} \% \mathrm{CdS}$, (e) PVA-2.0 wt $\%$ CdS. From these images, it was observed that nanoparticles were aglomerated at all concentrations at varying degree. These agglomerated $\mathrm{CdS}$ nanoparticles were seen homogeneously distributed throughout the PVA matrix at lower concentrations. Agglomeration of these nanoparticles lead to big masses as seen in some of the images such as in Figure 6b-6e. The white spots shown in all the SEM images (Figure 6) are CdS nanoparticles. As a result of agglomeration, the particle sizes were seen to increase with increase in filler concentration. The mean particle size obtained from the images was $40 \mathrm{~nm}$ (approxmately same as obtained from Scherrer formula) while the largest particle size obtained due to agglomeration was $240 \mathrm{~nm}$. The nanoparticles were seen to be dispersed closely to each other in PVA matrix with increase in nanofiller concentration from 0.5 to $2.0 \mathrm{wt} \%$. This is because with increase in nanofiller loading, the number of particles increases and so the interparticle distance decreases.

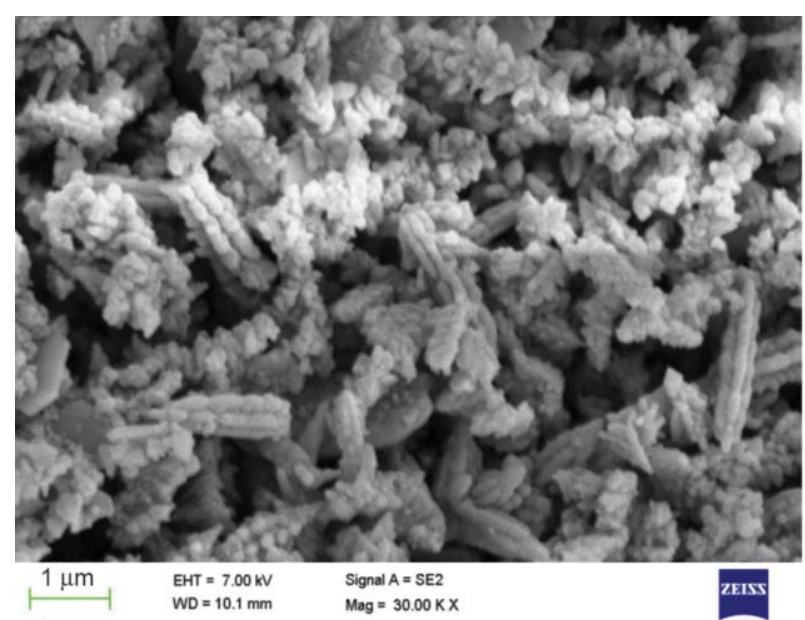

\subsection{Effect of CdS nanoparticles addition on different electrical properties of PVA matrix}

\subsubsection{Dielectric permittivity}

The effective dielectric permittivity in nanocomposites is determined by dielectric division in the bulk of the composite material. In the present case, these are: polarization associated with PVA as well as CdS nano particles and interfacial polarization at the PVAnanoparticle interfaces. The prepared nanocomposites have a large volume fraction of interfaces where interfacial polarizations are most likely to occur. Several dielectric properties of polymer nanocomposites have been evaluated in the past and the permittivity values in nanocomposites are reported to be lower than that of base polymers when insulating oxides are used as the fillers [12, 22-25].

In order to investigate the effect of nanoparticles on PVA matrix, CdS nanoparticles were incorporated into PVA matrix and analyzed for dielectric properties. Measurements of capacitance $C$ (in Farad) and loss tangent were made over the range from $4 \mathrm{~Hz}$ to $1 \mathrm{MHz}$. The dielectric constant $\left(\varepsilon_{\mathrm{r}}\right.$ or $\left.\varepsilon^{\prime}\right)$, dielectric loss $\left(\varepsilon^{\prime \prime}\right)$ and electrical conductivity values were calculated from capacitance and loss tangent using the Equations (1)-(3). The frequency-dependent $\varepsilon^{\prime}, \varepsilon^{\prime \prime}$ and $\tan \delta$ values of the PVA/CdS nanocomposites at different filler concentrations are presented in Figure 7 and 8 , respectively.

The dielectric parameter as a function of frequency is described by the complex permittivity in the form given by Equation (2):

$\varepsilon^{*}(\omega)=\varepsilon^{\prime}(\omega)-i \varepsilon^{\prime \prime}(\omega)$

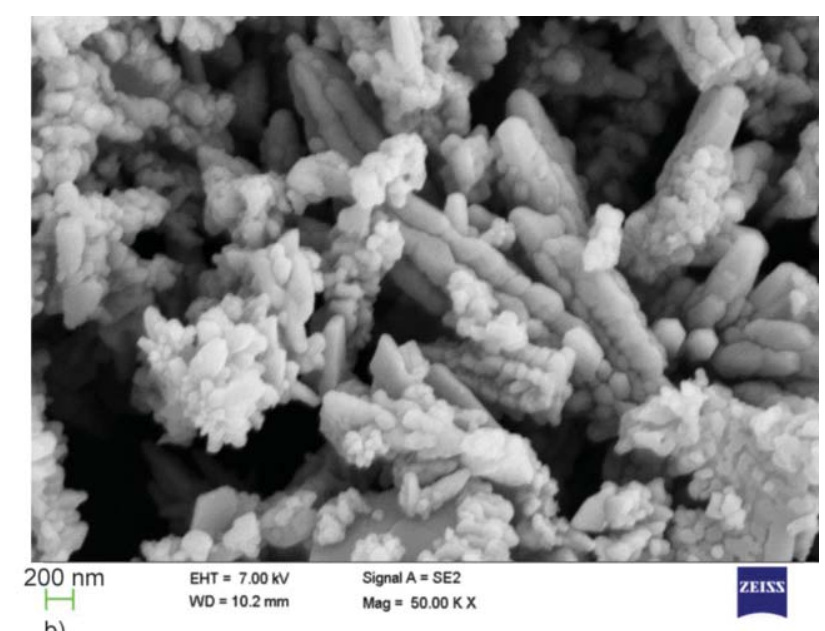

Figure 5. SEM image of CdS nanoparticles taken at (a) micrometre and (b) nanometre scale 

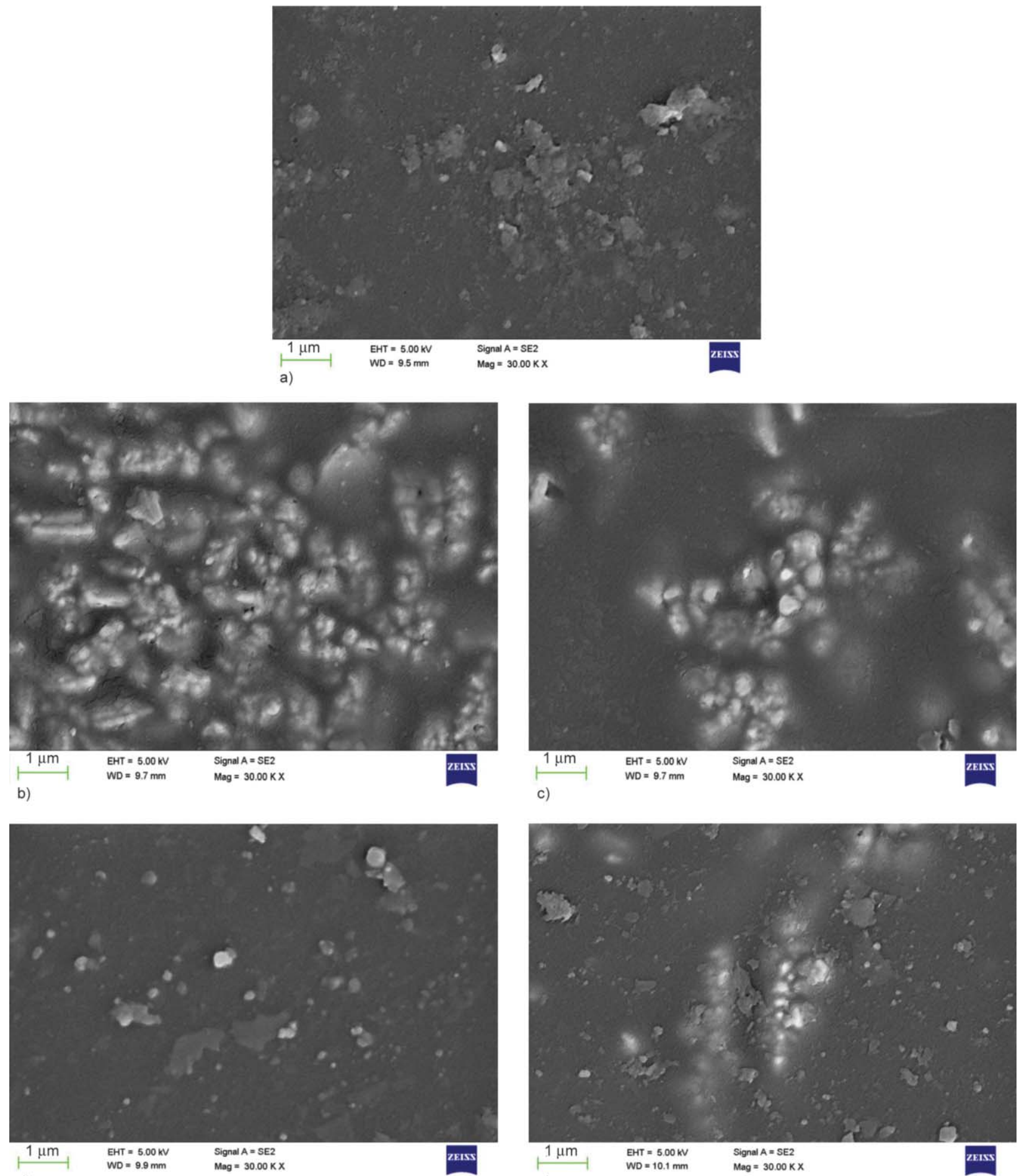

d)

e)

Figure 6. SEM photomicrographs of PVA loaded with CdS nanoparticles at (a) $0 \mathrm{wt} \%$, (b) $0.5 \mathrm{wt} \%$, (c) $1.0 \mathrm{wt} \%$, (d) $1.5 \mathrm{wt} \%$, (e) $2.0 \mathrm{wt} \%$

where $\varepsilon^{\prime}(\omega)$ is real part and $\varepsilon^{\prime \prime}(\omega)$ imaginary part are the components for energy storage and energy loss respectively in each cycle of the electric field. The measured capacitance $C$ was used to calculate the dielectric constant, $\varepsilon^{\prime}(\omega)$ using the Equation (3):
$\varepsilon^{\prime}(\omega)=\frac{C \cdot t}{A \cdot \varepsilon_{0}}$

where $t$ is the film thickness in [m], $A$ is surface area of sample in $\left[\mathrm{m}^{2}\right], \varepsilon_{0}$ is the permittivity of air $\left(8.85 \cdot 10^{-12} \mathrm{~F} / \mathrm{m}\right)$ and $\omega$ is the angular frequency in $\left[\mathrm{s}^{-1}\right]$ given by $\omega=2 \pi f$; and $f$ is frequency in $\left[\mathrm{s}^{-1}\right]$. 


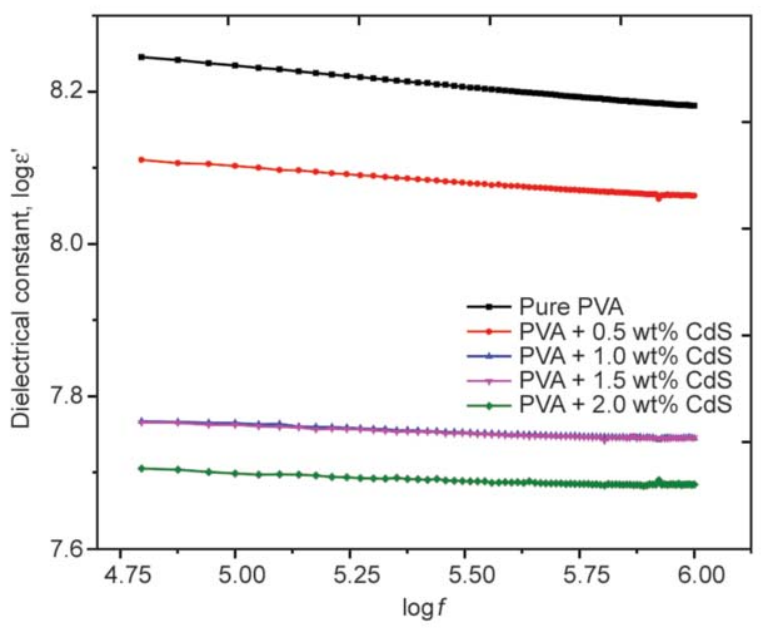

Figure 7. Dielectric constant of PVA/CdS nanocomposites as a function of $\log$ frequency

Whereas, the dielectric loss $\varepsilon^{\prime \prime}(\omega)$ is given by Equation (4):

$\varepsilon^{\prime \prime}(\omega)=\varepsilon^{\prime}(\omega) \tan \delta(\omega)$

where $\tan \delta(\omega)$ is tangent delta and $\varepsilon^{\prime}(\omega)$ is dielectric constant.

The dielectric properties of materials are mainly determined by their abilities to polarize at a given frequency. For multi component systems, when free charge carriers migrate through the material, space charges build up at the interfaces of the components remaining to the mismatch of the conductivities and dielectric constants of the materials at the interfaces $[26,27]$. This is called interfacial polarization. The interfacial polarization in polymers having structural in homogeneities (such as nanoparticles) can be identified by low-frequency dielectric measurement based on Maxwell-Wagner-Sillar's method [27-29]. The changes in the permittivity values as a function of frequency are attributed to dielectric relaxations especially at low frequency which is due to microBrownian motion of the whole chain (segmental movement). Nevertheless, these changes are also affected by the interfacial polarization process known as Maxwell-Wagner-Sillar, exist in heterogeneous dielectric materials and are produced by the travelling of charge carriers [30,31].

It is observed from Figure 7 and Figure 8 that the values of $\varepsilon^{\prime}, \varepsilon^{\prime \prime}$ and $\tan \delta$ were found to be strongly influenced by frequency. The value of $\varepsilon^{\prime}$, decreased with increasing frequency whereas the dielectric $\operatorname{loss} \varepsilon^{\prime \prime}$ increased with frequency. This shows that strong lowfrequency dispersion takes place that characterizes the frequency dependence of $\varepsilon^{\prime}$ and $\varepsilon^{\prime \prime}$ in PVA/CdS nanocomposite films. In general, there are four possible mechanisms that could contribute to the lowfrequency dielectric behaviour of PVA/CdS nanocomposites: electrode interface, $\mathrm{AC}$ electrical conductivity, dipole orientation and charge carriers. In principle, at low frequencies and temperatures, all four types of polarization mechanisms contribute to the values of $\varepsilon^{\prime}$ and $\varepsilon^{\prime \prime}$. As the frequency increases, the contributions of interfacial, dipolar, and ionic polarizations become ineffective, leaving behind only the AC electrical conductivity parameter. Furthermore, decrease in $\varepsilon^{\prime}$ with increasing frequency can be explained by the fact that as the frequency increased, the interfacial dipoles had less time to orient themselves in the direction of the alternating field. However, the value of $\varepsilon^{\prime \prime}$ increased with increasing frequency, which can be credited to the high interfacial traps formed at the PVA/CdS interface that negatively influences the electrical properties [32] that illustrate the dependence of various dielectric behaviors on $\mathrm{CdS}$ content and on the frequency of the applied AC field.

From Figure 7 it is observed that $\varepsilon^{\prime}$ value gradually decreased with increase in CdS loading from 0.5 to $1 \mathrm{wt} \%$ in the PVA matrix and further increase in CdS content had no effect and $\varepsilon^{\prime}$ was observed to be constant for 1 and $1.5 \mathrm{wt} \%$. Also, less difference was observed between $\varepsilon^{\prime}$ values for $1,1.5$ and $2.0 \mathrm{wt} \%$ as compared to the $\varepsilon^{\prime}$ values for $0,0.5$ and $1.0 \mathrm{wt} \% \mathrm{CdS}$ content. These results suggest that there is an existing threshold $\mathrm{CdS}$ content for the dielectric behavior of these nanocomposites.

As shown by Figure 5, the majority of nano-sized CdS particles were well-dispersed in the PVA matrix when the CdS content exceeded $1 \mathrm{wt} \%$ and these well-dispersed particles emerge as mini-capacitors within the composites (Figure 5d and 5e). Hence it can be said that the high values of dielectric constant for PVA/CdS composite films observed is the result of the accumulation of these nano-sized capacitors. Since these particles were fixed within the PVA matrix, the charge associated with an individual particle was confined to a small area surrounding the particle and could not jump to adjacent particles. In the investigation of a CdS/PVA composite material pre- 


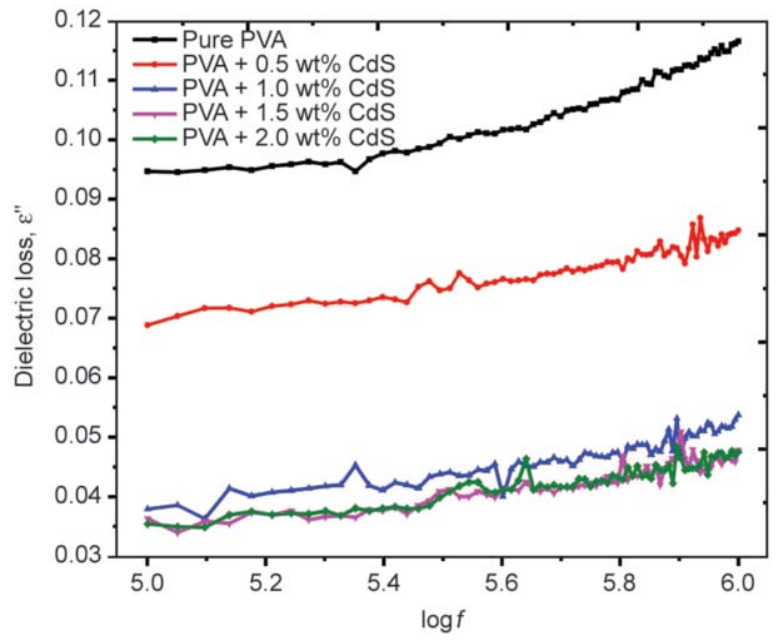

Figure 8. Dielectric loss of PVA/CdS nanocomposites as a function of $\log$ frequency

pared by sonication in present study, it is found that that the CdS nano-crystalline domains $(\sim 90 \mathrm{~nm})$ can give rise to large dielectric constants.

\subsubsection{Dielectric loss}

Dielectric loss is the portion of energy of an alternating electric field in a dielectric medium that is converted into heat. It can be expressed in terms of either the loss angle $(D)$ or corresponding loss tangent $(\tan \delta)$. Figure 8 shows the effect of frequency on dielectric loss for PVA/CdS nanocomposites. It is seen that the dielectric loss increases with increase in frequency. This increase is substantial at high frequencies in the range of $10^{5}-10^{6} \mathrm{~Hz}$ and may be due to heat generated within the composite as a result of rapid alignment of dipoles with the rapidly changing direction of electric field. The dielectric losses may have also increased because of increase in conduction losses with increase in frequency. In spite of these factors, the dielectric loss behaviour with frequency seems to be quite complicated and requires further study.

\subsubsection{AC conductivity}

$\mathrm{AC}$ conductivity is the alternating conductivity of sample that arises from the motion of charge carriers through the polymer and is measured using the Equation (5) [33-35]:

$$
\sigma_{\mathrm{ac}}=\frac{G_{\mathrm{p}} \cdot t}{A}
$$

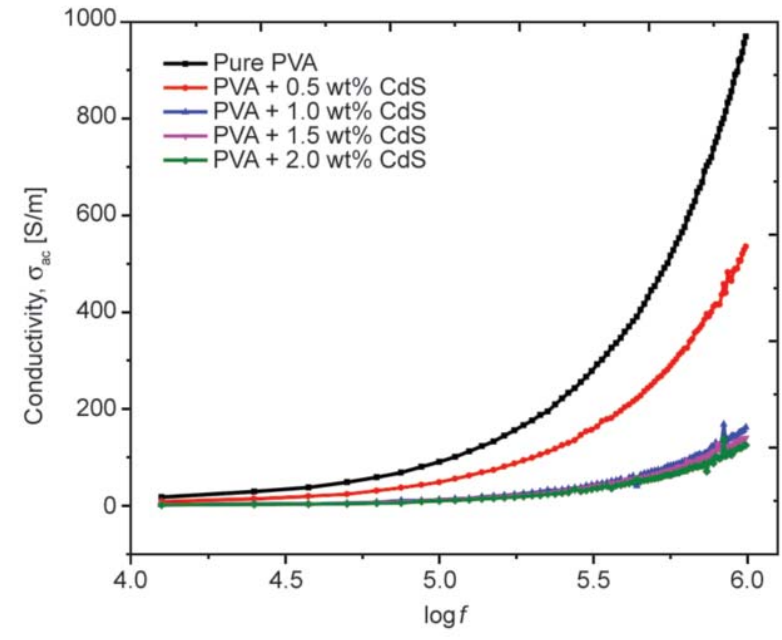

Figure 9. AC Conductivity of PVA/CdS nanocomposites as a function of $\log$ frequency

where $G_{\mathrm{p}}$ is the conductance, $t$ is the film thickness $[\mathrm{m}], A$ is surface area of sample $\left[\mathrm{m}^{2}\right]$.

Figure 9 illustrates the dependence of AC electrical conductivity $\left(\sigma_{\mathrm{ac}}\right)$ on frequency [36]. The variation is studied in the frequency range from $4 \mathrm{kHz}$ to $1 \mathrm{MHz}$ at room temperature for the PVA/CdS composites. It can be noted that the AC electrical conductivity generally increased with increasing frequency; in particular, a sharp increase in $\sigma_{\mathrm{ac}}$ is found beyond $1 \mathrm{kHz}$ frequency. This may be due to increased electronic interaction processes taking place inside the composites as a result of which the composites became more relatively conductive. In PVA, as the bond rotates with increased frequency, the existing flexible polar groups cause dielectric transitions. This changes the composition of the polymer chains due to the formation of charge transfer complexes. The $\mathrm{AC}$ conductivity increases [37] and polymer chains become more flexible.

\subsubsection{Loss tangent ( $D$ or $\tan \delta$ )}

Variation in loss tangent $(\tan \delta$ ) of PVA/CdS composites as a function of frequency is shown in Figure 10. It can be seen from the figure that $\tan \delta$ decreased initially and then increased with increasing frequency in the range from $4 \mathrm{~Hz}$ to $1 \mathrm{MHz}$ passing through a minimum at $6.5 \cdot 10^{4} \mathrm{~Hz}$ frequency gradually. The decrease was seen at lower concentrations of $\mathrm{CdS}$ nanofiller. The increase in this value indicates the increase in loss storage ratio and hence the composite becomes a semi-conductor and is similar to the ob- 


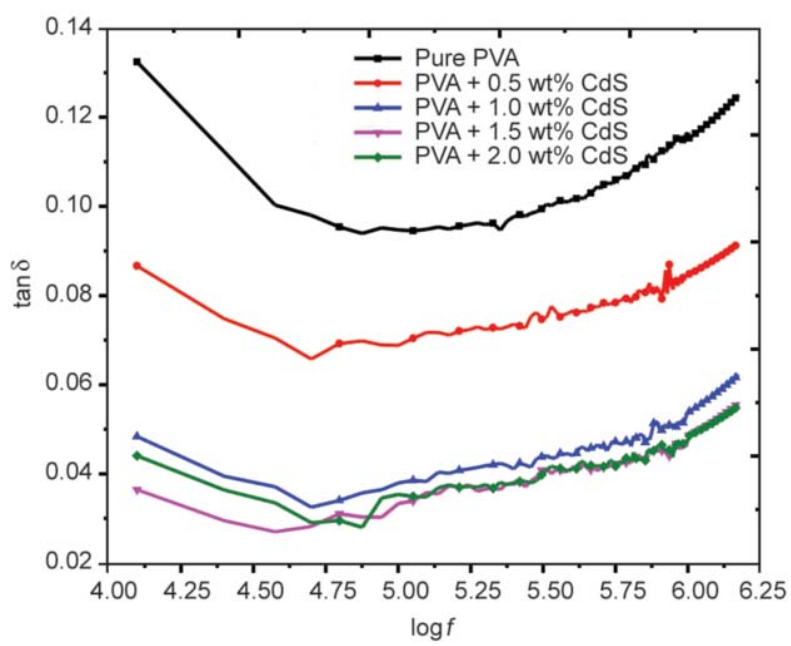

Figure 10. Loss tangent of PVA/CdS nanocomposites as a function of $\log$ frequency

servations made by Chao-Hsien Ho et al. [38] from the studies on PANI-DBSA/PAA (polyaniline, dodecyl-benzene sulfonate and poly-acrylic acid) films. These experimental results show that $\varepsilon^{\prime}, \varepsilon^{\prime \prime}$ and $\tan \delta$ had a strong dependence on the measured frequency. The capacitance of the PVA/CdS composites at high frequencies in the accumulation region was basically controlled by the dielectric properties of the bulk insulator.

\section{Conclusions}

$\mathrm{PVA} / \mathrm{CdS}$ nanocomposites containing varying weight percentages of CdS nanoparticles were prepared by solution intercalation technique. Effects of CdS nanoparticles on structural and electrical properties of PVA films were observed. Various peaks obtained in FTIR analysis showed good physical interaction between PVA matrix and nano CdS. SEM analysis showed porous and acicular $\mathrm{CdS}$ nanoparticles which tend to agglomerate at higher concentrations in the polymer matrix. DSC analysis shows that presence of nanoparticles in PVA matrix influence thermal properties like $T_{\mathrm{g}}$ and $T_{\mathrm{m}}$ and heat capacity. Electrical properties of PVA/CdS nanocomposites have been reported for the first time probably by hydrothermal method of synthesizing the nanomaterial. These properties were observed to be strongly dependent upon applied frequency and CdS nanofiller content. Dielectric constant decreased with increase in frequency and with increase in filler concentration; AC conductivity and dielectric loss increased with frequency and decreased with increase in CdS content. The loss tangent increased with increase in concentration of nanofiller showed that the CdS/PVA nanocomposite films can be good semiconductors.

\section{Acknowledgements}

The authors would like to extend their kind gratitude towards Department of Chemistry, MSRIT for providing the necessary facilities to synthesize the materials. They would also like to thank MSRIT Alumni Association for providing funds required to carry out this research study. A portion of this research was also performed using facilities at CeNSE, funded by Department of Information Technology, Govt. of India located at Indian Institute of Science, Bangalore. DSC analysis was carried out at NETZSCH Technologies India Pvt. LtdAnalysis and Testing located in Chennai, Tamil Nadu.

\section{References}

[1] Zhang M., Dreschler M., Müller A. H. E.: Templatecontrolled synthesis of wire-like cadmium sulfide nanoparticle assemblies within core-shell cylindrical polymer brushes. Chemistry of Materials, 16, 537-543 (2004).

DOI: $10.1021 / \mathrm{cm} 034760 \mathrm{v}$

[2] Zhao H., Douglas E. P.: Preparation of corona-embedded CdS nanoparticles. Chemistry of Materials, 14, 1418-1423 (2002). DOI: $10.1021 / \mathrm{cm} 011581$

[3] Kim J-Y., Kim H-M., Shin D-H., Ihn K-J.: Synthesis of $\mathrm{CdS}$ nanoparticles dispersed within poly(urethane acrylate-co-styrene) films using an amphiphilic urethane acrylate nonionomer. Macromolecular Chemistry and Physics, 207, 925-932 (2006). DOI: $10.1002 / \mathrm{macp} .200600031$

[4] Pardhan B., Sharma A. K., Ray A. K.: Conduction studies on chemical bath-deposited nanocrystalline CdS thin films. Journal of Crystal Growth, 304, 388-392 (2007).

DOI: $10.1016 /$ j.jcrysgro.2007.03.041

[5] Pattabi M., Amma B. S., Manzoor K., Sanjeev G.: Effect of $8 \mathrm{MeV}$ electron irradiation on the optical properties of PVP capped CdS nanoparticles in PVA matrix. Solar Energy Materials and Solar Cells, 91, 1403-1407 (2007). DOI: $10.1016 /$ j.solmat.2007.04.015

[6] Wang H., Fang P., Chen Z., Wang S.: Synthesis and characterization of CdS/PVA nanocomposite films. Applied Surface Science, 253, 8495-8499 (2007).

DOI: $10.1016 /$ j.apsusc. 2007.04 .020

[7] Rao J. K., Raizada A., Ganguly D., Mankad M. M., Satayanarayna S. V., Madhu G. M.: Investigation of structural and electrical properties of novel $\mathrm{CuO}-\mathrm{PVA}$ nanocomposite films. Journal of Materials Science, 50, 7064-7074 (2015).

DOI: $10.1007 / \mathrm{s} 10853-015-9261-0$ 
[8] Rao J. K., Raizada A., Ganguly D., Mankad M. M., Satayanarayna S. V., Madhu G. M.: Enhanced mechanical properties of polyvinyl alcohol composite films containing copper oxide nanoparticles as filler. Polymer Bulletin, 72, 2033-2047 (2015).

DOI: $10.1007 / \mathrm{s} 00289-015-1386-4$

[9] Rashmi S. H., Raizada A., Madhu G. M., Kittur A. A., Suresh R., Sudhina H. K.: Influence of zinc oxide nanoparticles on structural and electrical properties of polyvinyl alcohol films. Plastics, Rubber and Composites: Macromolecular Engineering, 44, 33-39 (2015). DOI: $10.1179 / 1743289814$ Y.0000000115

[10] Maeda S., Armes S. P.: Surface area measurements on conducting polymer-inorganic oxide nanocomposites. Synthetic Metals, 73, 151-155 (1995). DOI: 10.1016/0379-6779(95)03315-7

[11] Huang J-C., Zhu Z-K., Yin J., Qian X-F., Sun Y-Y.: Poly(etherimide)/montmorillonite nanocomposites prepared by melt intercalation: Morphology, solvent resistance properties and thermal properties. Polymer, 42, 873-877 (2001). DOI: $10.1016 / \mathrm{S} 0032-3861(00) 00411-0$

[12] Tanaka T.: Dielectric nanocomposites with insulating properties. IEEE Transactions on Dielectrics and Electrical Insulation, 12, 914-928 (2005).

DOI: 10.1109/TDEI.2005.1522186

[13] Jayasekara R., Harding I., Bowater I., Christie G. B. Y., Lonergan G. T.: Preparation, surface modification and characterisation of solution cast starch PVA blended films. Polymer Testing, 23, 17-27 (2004).

DOI: 10.1016/S0142-9418(03)00049-7

[14] Kokabi M., Sirousazar M., Hassan Z. M.: PVA-clay nanocomposite hydrogels for wound dressing. European Polymer Journal, 43, 773-781 (2007). DOI: $10.1016 /$ j.eurpolymj.2006.11.030

[15] Datta A., Panda S. K., Chaudhuri S.: Synthesis and optical and electrical properties of $\mathrm{CdS} / \mathrm{ZnS}$ core/shell nanorods. The Journal of Physical Chemistry C, 111, 17260-17264 (2007). DOI: $10.1021 / j p 076093 p$

[16] Rudko G. Y., Kovalchuk A. O., Bondarenko V. A., Fediv V. I., Gule E. G.: Tunable electrophysical properties of composites nano-CdS/polyvinyl alcohol. Materials Chemistry and Physics, 148, 77-81 (2014). DOI: 10.1016/j.matchemphys.2014.07.014

[17] Madhu G. M., Raj M. A. L. A., Pai K. V. K., Rao S.: Photodegradation of methylene blue dye using UV/ $\mathrm{BaTiO}_{3}, \mathrm{UV} / \mathrm{H}_{2} \mathrm{O}_{2}$ and $\mathrm{UV} / \mathrm{H}_{2} \mathrm{O}_{2} / \mathrm{BaTiO}_{3}$ oxidation processes. Indian Journal of Chemical Technology, 14, 139-144 (2007).

[18] Oliveira J. F. A., Milão T. M., Araújo V. D., Moreira M. L., Longo E., Bernardi M. I. B.: Influence of different solvents on the structural, optical and morphological properties of CdS nanoparticles. Journal of Alloys and Compounds, 509, 6880-6883 (2011). DOI: $10.1016 /$ j.jallcom.2011.03.171
[19] Bhadra J., Sarkar D.: Electrical and optical properties of polyaniline polyvinyl alcohol composite films. Indian Journal of Pure and Applied Physics, 48, 425-428 (2010).

[20] Aneeqa S., Saadat A. S., Salamat A.: Fabrication and characterization of CdS nanoparticles annealed by using different radiations. International Journal of Chemical, Molecular, Nuclear, Materials and Metallurgical Engineering, 4, 532-539 (2010).

[21] Raut B. T., Chougule M. A., Ghanwat A. A., Pawar R. C., Lee C. S., Patil V. B.: Polyaniline-CdS nanocomposites: Effect of camphor sulfonic acid doping on structural, microstructural, optical and electrical properties. Journal of Materials Science: Materials in Electronics, 23, 2104-2109 (2012). DOI: $10.1007 / \mathrm{s} 10854-012-0708-7$

[22] Zhang L., Wu P., Li Y., Cheng Z-Y., Brewer J. C.: Preparation process and dielectric properties of $\mathrm{Ba}_{0.5} \mathrm{Sr}_{0.5} \mathrm{TiO}_{3}-$ P(VDF-CTFE) nanocomposites. Composites Part B: Engineering, 56, 284-289 (2014). DOI: $10.1016 /$ j.compositesb.2013.08.029

[23] Dang Z-M., Yuan J-K., Zha J-W., Zhou T., Li S-T., Hu G-H.: Fundamentals, processes and applications of highpermittivity polymer-matrix composites. Progress in Materials Science, 57, 660-723 (2012).

DOI: $10.1016 /$ j.pmatsci.2011.08.001

[24] Panda M., Srinivas V., Thakur A. K.: On the question of percolation threshold in polyvinylidene fluoride/nanocrystalline nickel composites. Applied Physics Letters, 92, 132905/1-132905/4 (2008).

DOI: $10.1063 / 1.2900710$

[25] Cao Y., Irwin P. C., Younsi K.: The future of nanodielectrics in the electrical power industry. IEEE Transactions on Dielectrics and Electrical Insulation, 11, 797-807 (2004).

DOI: $10.1109 /$ TDEI.2004.1349785

[26] Li D., Leung Y. H., Djurišić A. B., Liu Z. T., Xie M. H., Gao J., Chan W. K.: CuO nanostructures prepared by a chemical method. Journal of Crystal Growth, 282, 105111 (2005). DOI: $10.1016 /$ j.jcrysgro.2005.04.090

[27] Ku C. C., Liepins R.: Electrical properties of polymers: Chemical principles. Hanser, Munich (1987).

[28] Maxwell J. C.: A Treatise on electricity and magnetism. Clarendon Press, Oxford (1954).

[29] Wagner K. W.: Zur Theorie der unvollkommenen Dielektrika. Annalen der Physik Wiley, 40, 817-855 (1913). DOI: 10.1002/andp.19133450502

[30] Latif I., AL-Abodi E. E., Dhefaf H. B., Al Khafagi J.: Preparation, characterization and electrical study of (carboxymethylated polyvinyl alcohol/ZnO) nanocomposites. American Journal of Polymer Science, 2, 135-140 (2012).

DOI: 10.5923/j.ajps.20120206.01

[31] Patsidis G. C., Psarras A.: Dielectric behaviour and functionality of polymer matrix-ceramic $\mathrm{BaTiO}_{3}$ composites. Express Polymer Letters, 2, 718-726 (2008). DOI: $10.3144 /$ expresspolymlett.2008.85 
[32] Zhang L. D., Zhang H. F., Wang G. Z., Mo C. M., Zhang Y.: Dielectric behaviour of nano- $\mathrm{TiO}_{2}$ bulks. Physica Status Solidi (a), 157, 483-491 (1996).

DOI: $10.1002 /$ pssa.2211570232

[33] Dyre J. C., Schrøder T. B.: Universality of AC conduction in disordered solids. Reviews of Modern Physics, 72, 873-892 (2000).

DOI: 10.1103/RevModPhys.72.873

[34] Harun M. H., Saion E., Kassim A., Hussain M. Y., Mustafa I. S., Omer M. A. A.: Temperature dependence of AC electrical conductivity of PVA-PPy- $\mathrm{FeCl}_{3} \mathrm{com}$ posite polymer films. Malaysian Polymer Jounal, 3, 2431 (2008).

[35] Meera J., Sumithra V., Seethu R., Prajeshkumar J. M.: Dielectric properties of nanocrystalline $\mathrm{ZnS}$. SB Academic Review, 1, 93-100 (2010).

[36] Tripathi R., Kumar A., Sinha T. P.: Dielectric properties of CdS nanoparticles synthesized by soft chemical route. Pramana: Journal of Physics, 72, 969-978 (2009). DOI: 10.1007/s12043-009-0089-5

[37] Bhajanti R. F., Ravindrachary V., Harisha A., Ranganathiah G., Kumaraswamy G. N.: Effect of barium chloride doping on PVA microstructure: Positron annihilation study. Applied Physics A, 87, 797-805 (2007). DOI: $10.1007 / \mathrm{s} 00339-007-3923-y$
[38] Ho C-H., Liu C-D., Hsieh C-H., Hsieh K-H., Lee S-N.: High dielectric constant polyaniline/poly(acrylic acid) composites prepared by in situ polymerization. Synthetic Metals, 158, 630-637 (2008). DOI: $10.1016 /$ j.synthmet.2008.04.014

[39] El-Tantawy F., Abdel-Kader K. M., Kaneko F., Sung Y. K.: Physical properties of CdS-poly (vinyl alcohol) nanoconducting composite synthesized by organosol techniques and novel application potential. European Polymer Journal, 40, 415-430 (2004).

DOI: $10.1016 /$ j.eurpolymj.2003.10.013

[40] Pal K., Banthia A. K., Majumdar D. K.: Preparation and characterization of polyvinyl alcohol-gelatin hydrogel membranes for biomedical applications. AAPS PharmSciTech, 8, E142-E146 (2007).

DOI: $10.1208 /$ pt080121

[41] Giribabu K., Suresh R., Manigandan R., Vijayaraj A., Prabu R., Narayanan V.: Cadmium sulphide nanorods: Synthesis, characterization and their photocatalytic activity. Bulletin of the Korean Chemical Society, 33, 2910-2916 (2012).

DOI: $\underline{10.5012 / \mathrm{bkcs} .2012 .33 .9 .2910}$ 